\title{
Research Paper: Complications of Laparoscopic and Laparotomy Surgeries in the Department of Tehran Legal Medical Committee in 2011-2016
}

Fares Najari $^{1^{*}}$ Q, Babak Mostafazadeh ${ }^{1}$ Q, Leila Soleimani Natanzi ${ }^{1}$

1. Department of Forensic Medicine and Toxicology, School of Medicine, Shahid Beheshti University of Medical Sciences, Tehran, Iran.

$\begin{aligned} & \text { Use your device to scan } \\ & \text { and read the article online }\end{aligned}$
$\begin{aligned} & \text { Crtation: Najari F, Mostafazadeh B, Soleimani Natanzi L. Complications of Laparoscopic and Laparotomy Surgeries in } \\ & \text { the Department of Tehran Legal Medical Committee in 2011-2016. International Journal of Medical Toxicology and Forensic } \\ & \text { Medicine. 2019; 9(2):83-90. https://doi.org/10.32598/ijmtfm.v9i2.24989 }\end{aligned}$
dof" https://doi.org/10.32598/ijmtfm.v9i2.24989

\section{(a) 03}

Article info:

Received: 28 Aug 2018

First Revision: 25 Sep 2018

Accepted: 05 Jan 2019

Published: 01 Apr 2019

\section{Keywords:}

Medical malpractice,

Laparoscopy, Laparotomy, Medical complaint

\section{ABSTRACT}

Background: A major challenge in medicine is patients' dissatisfaction and complaints against doctors. Medical complaints in Iran, similar to the other countries, have a growing trend. Over the past two decades, the implementation of laparoscopic surgery rapidly grew in many countries. The current study aimed to investigate complaints against surgeons in laparoscopic surgeries, compared to open surgeries.

Methods: The current cross-sectional study was conducted on all laparotomy and laparoscopic surgery complaint cases. The medical records were extracted based on the study variables, using a researcher-made questionnaire. To analyze the obtained data, frequency tables were used and to investigate the relationship between variables, Chi-Squared and Fisher's Exact tests were employed.

Results: A total of 369 medical complaint cases were brought to the Department of Tehran Legal Medical Committee, Tehran, Iran, from 2011 to 1016. The Mean \pm SD age of studied patients was $45.8 \pm 13.4$ years. The most frequent medical complaint cases were against physicians working at private hospitals. In addition, most complaints were after laparotomy cases. More than half of the cases were voted on the malpractice of physicians. The frequency of postoperative infections was significantly higher in laparoscopic surgeries. The frequency of sentence for malpractice was significantly higher in laparoscopic surgeons, compared to laparotomy ones.

Conclusion: Physicians' knowledge about legal medical issues and building intimate and trustful relationship with patients along with the provision of desirable healthcare services can be effective in reducing medical error complaints.

\section{* Corresponding Author:}

Fares Najari, MD.

Address: Department of Forensic Medicine and Toxicology, School of Medicine, Shahid Beheshti University of Medical Sciences, Tehran, Iran. Tel: +98 (912) 3195140

E-mail:najar.hospital@sbmu.ac.ir 


\section{Introduction}

$\mathbf{P}$

hysicians have important professional and ethical responsibilities that ensure trust and confidence and maintain their dignity and spiritual status in society [1]. A major challenge in medical careers is patients' dissatisfaction and complaints against physicians. Such complaints affect the personal and professional life of the subjected physicians [2]. In the medical profession, similar to any other professions, there are possibilities of error and failure [3].

If physicians fail to meet the professional responsibilities in the examination, timely diagnosis and treatment, meticulous surgery, follow-up, consultancy, and guidance based on scientific and technical standards, they are sentenced for medical malpractice. Medical doctors are expected to perform all diagnostic practices, history taking, examinations, required clinical and paraclinical tests, and if necessary, consult other colleagues before initiating treatment. Failure to follow such medical practices and technical procedures may result in medical malpractice, which can lead to a patient's complaint [4].

Medical malpractice includes negligence, the lack of skills, non-compliance with government regulations, and recklessness. Recklessness is the most severe form of medical malpractice. Recklessness indicates the failure of a physician in meeting responsibilities [5]; e.g. not taking a medical history or overlooking an accurate examination [6]. Negligence comprises the actions the physician was not supposed to do; e.g. circumcision or penicillin injection in a clinic with no cardiovascular resuscitation facility [5]. The lack of skills refers to the inability to perform actions that require special skills due to inexperience or medical knowledge deficit, such as insufficient experience in skin treatments, and the rupture of the artery during surgery while the surgeon is not qualified to repair it [6].

Failure to comply with government regulations comprises not paying attention to the regulations, circulars, and instructions issued by the supreme administrative authorities, Iran Medical Council, and the Ministry of Health and Medical Education, which manage the medical careers [7]. Complaints against physicians are important from two aspects; first, complaints against them result in the waste of time and money, and second, they cause severe stress, which in turn reduces their working quality [3]. International reports about the extent of complaints against physicians are growing despite extensive advances in diagnostic and therapeutic ser- vices. In Iran, medical errors are usually referred to as "medical malpractice" or "undesirable practice of physicians"; both are legal terms [7].

The medical error complaints in Iran are growing, similar to the other countries in the world [8]. The main reasons for the increased medical complaints are the physicians' lack of knowledge about legal issues and regulations governing medical practice and their responsibilities towards patients [9]. Research projects performed by the Department of Research and Education at the Iranian Legal Medicine Organization reported a $12 \%$ increase in the total number of raised cases from 13614 to 15241 [8].

The aviation injuries risk is one in a million flights, while this risk in receiving medical care in hospitals is one in 300. According to the World Health Organization estimations, 7 million people in the world annually face debilitating complications following surgery, of whom more than one million die. On a global scale, the financial burden of medical errors is estimated to be about USD 42 billion [10]. Over the past two decades, the implement of laparoscopic surgery grew rapidly in many countries. This minimally invasive surgical procedure is considered as the most important evolution in surgical techniques in the last century [11].

Reports indicate that $65 \%$ of medical errors are preventable [12]. Most patients desire to choose low-risk surgical methods (laparoscopy), compared with laparotomy. Thus, the current study compared complaints against laparoscopy and laparotomy surgeons. The obtained data are beneficial to prevent complications and subsequent complaints and the efforts to perform such practices more cautiously.

\section{Materials and Methods}

The current cross-sectional study was conducted on all closed cases on the complaints against laparotomy or laparoscopic surgeons referred to the Department of Tehran Legal Medical Committee in Tehran City, Iran, from 2011 to 2016. The inclusion criteria were all complete cases relevant to the study variables against general surgeons, obstetricians, gynecologists, anesthesiologists, etc. In laparoscopic or laparotomy procedures. Cases with incomplete information or restricted access were excluded from the study. The study was conducted after obtaining permission from the authorities of the Iranian Legal Medicine Organization. 
All of the information about the name of physicians, patients, hospitals, and experts remained confidential and the forms were completed anonymously. By referring to the Department of Tehran Legal Medical Committee, complaints against surgery departments were collected; then, the extracted data were recorded in a researcher-made questionnaire.

By the researcher-made questionnaire and based on the study variables, records, including the complainants' characteristics such as age, gender, and the operated organ were obtained. In addition, the defendants' characteristics such as age, specialty, academic degree, and surgical variables (e.g. the place in which the lawsuit filed, surgery type, emergency or elective referral, the occurred complication, commission vote, and the failure type) were extracted. The complainants were real and legal persons who brought their complaints to the Judiciary Special Medical Malpractice Court. The defenders were the surgeons that the complaints were brought against them.

The current study also aimed to determine the frequency of complaints related to laparoscopic surgeries and compare them with those of the laparotomy cases against obstetrics and gynecology, anesthesia, and other surgeons. The current census-based study was performed on all of the relevant files brought during the study period. The obtained data were analyzed in SPSS using descriptive and analytical tests. Quantitative factors were expressed as Mean $\pm \mathrm{SD}$ and qualitative factors as frequency and percentage. To interpret the variables, frequency tables were used, and for establishing the relationship between variables, Chi-Squared and Fisher's Exact tests were employed. $\mathrm{P}<0.05$ was considered as the level of significance.

\section{Results}

From 2011 to 2016, a total of 369 medical complaints related to laparoscopic and laparotomy surgical procedures were brought to the Department of Tehran Legal Medical Committee. Females had more frequently filed complaints against medical doctors than males. According to Table 1, the number of female complainants was 4 times higher than that of males. The Mean \pm SD age of patients (complainants) was $45.8 \pm 13.4$ years. Patients in the age range of $30-49$ years $(56.9 \%)$ constituted the highest relative frequency of medical complaints. Patients in the age range of $\geq 70$ years $(5.7 \%)$ comprised the least filed cases. Most complaints (53\%) were attributed to private hospitals, followed by teaching (24\%) and public $(21.3 \%)$ hospitals. The least complaints belonged to clinics $(1.7 \%)$.

The female reproductive system (i.e. uterus and ovaries) had the highest relative frequency of medical complaints $(46.2 \%)$, followed by gallbladder surgery $(36.8 \%)$. The majority of medical complaints $(81.1 \%)$ were attributed to optional surgical procedures. Laparotomy constituted the majority of surgical cases (58.5\%). In the current study, the Mean \pm SD age of surgeons (defendants) was $56 \pm 10.7$ years. Surgeons in the age range of 40-59 years constituted the majority of defendants $(52.8 \%)$. Only $5.1 \%$ of surgeons aged $<40$ years. In total, $95 \%$ of physicians aged $\geq 40$ years.

Complaints against the general surgeons (54\%) accounted for the majority of cases, followed by gynecological surgeons (40.1\%). Complaints against anesthesiologists and other specialists had the least percentages (3\% each). A vast majority $(94.6 \%)$ of the complaint cases were against specialists. Based on the Medical Commission's final vote, $53.9 \%$ of the complaints against physicians were on their failure. Table 1 presents the demographic characteristics of patients and physicians. Noncompliance in the total frequency of some variables is due to the missing data in the forms.

Table 2 indicates that the distribution of the files was formed based on the occurred complication and the type of failure. Among the reported complications, rupture and damage to the adjacent organ (34.7\%) were the most frequent post-surgery complications, followed by postoperative infection in one-fourth of the cases (25.2\%). Postoperative bleeding had the least percentage of reported complications $(3.8 \%)$. Approximately one-third of surgical procedures $(30.4 \%)$ resulted in patient deaths. Of the 369 surgical procedures leading to medical complaints, $43.6 \%$ required repeat surgery.

According to Table 2, the delayed diagnosis was the most frequent failure (23\%), followed by the surgeons' technical errors $(21.4 \%)$. The technical bugs of the devices used during surgery were the least reported cases (2.2\%). Recklessness (29\%) had the highest relative frequency in physicians' failure, according to legal medicine disciplines, followed by negligence $(18.7 \%)$. The lack of compliance with government legislation (5.7\%) shaped the least cases of physicians' malpractice, according to forensic medicine.

Table 3 compares the complications caused by laparoscopic and laparotomy surgeries. The relative frequency of postoperative infections was significantly higher in 
Table 1. The demographic characteristics of patients and surgeons in the medical complaints filed for laparoscopic and laparotomy surgeries

\begin{tabular}{|c|c|c|c|c|c|}
\hline Variable & Classification & $\begin{array}{l}\text { Absolute (Relative) } \\
\text { Frequency }\end{array}$ & Variable & Classification & $\begin{array}{l}\text { Absolute (Rela- } \\
\text { tive) Frequency }\end{array}$ \\
\hline \multirow[b]{2}{*}{ Gender (patients) } & Female & $298(81.4)$ & \multirow{2}{*}{ The type of surgery } & Laparotomy & $210(58.5)$ \\
\hline & Male & 68(18.6) & & Laparoscopy & $149(41.5)$ \\
\hline \multirow{4}{*}{ Age group, $y$ (patients) } & $<30$ & $36(9.8)$ & \multirow{4}{*}{$\begin{array}{l}\text { Age group, y } \\
\text { (surgeon) }\end{array}$} & $<40$ & $19(5.1)$ \\
\hline & $30-49$ & $210(56.9)$ & & $40-59$ & 195(52.8) \\
\hline & $50-69$ & $102(27.6)$ & & & \\
\hline & $\geq 70$ & $21(5.7)$ & & $60 \leq$ & $155(42)$ \\
\hline \multirow{4}{*}{$\begin{array}{l}\text { The center patient } \\
\text { referred to receive } \\
\text { medical services }\end{array}$} & Teaching hospital & $88(24)$ & \multirow{4}{*}{$\begin{array}{l}\text { Surgeon's } \\
\text { specialty }\end{array}$} & General & $198(54)$ \\
\hline & Public hospital & $78(21.3)$ & & $\begin{array}{l}\text { Females ob- } \\
\text { stetrician and } \\
\text { gynecologist }\end{array}$ & $147(40.1)$ \\
\hline & Private hospital & 194(53) & & Anesthesiologist & $11(3)$ \\
\hline & Day Clinic & $6(1.7)$ & & Other specialties & $11(3)$ \\
\hline \multirow{4}{*}{ Operated organ } & Uterus and ovaries & $166(46.2)$ & \multirow{4}{*}{$\begin{array}{l}\text { The academic } \\
\text { degree of surgeon }\end{array}$} & Specialist & 349(94.6) \\
\hline & Gallbladder & $132(36.8)$ & & Fellowship & $11(3)$ \\
\hline & Stomach & $32(8.9)$ & & & \\
\hline & Other organs & $29(8.1)$ & & Sub-specialist & $9(2.4)$ \\
\hline \multirow{2}{*}{ Therapeutic practice } & Emergency & 69(18.9) & \multirow{2}{*}{$\begin{array}{l}\text { The final vote of the } \\
\text { commission }\end{array}$} & Sentenced & 199(53.9) \\
\hline & Elective & $296(81.1)$ & & Acquitted & $170(46.1)$ \\
\hline
\end{tabular}

laparoscopy cases, compared to laparotomy procedures. About one-third of the laparoscopic surgeries developed postoperative infections, while this proportion was $17.6 \%$ in laparotomy.

Damage or rupture of the adjacent visceral tissue was also significantly higher in laparoscopic surgeries, compared to laparotomy ones. About $44.3 \%$ of the laparoscopic and $27.6 \%$ of laparotomy surgeries reported damage or the rupture of adjacent visceral tissue. The relative frequency of death was also higher in laparoscopic surgery, compared to laparotomy; however, the difference was not statistically significant. Furthermore, repeat surgery was higher required in laparoscopic surgery than laparotomy. This was to such an extent that $57 \%$ of laparoscopic surgeries needed repeat surgery, while this rate was $34.3 \%$ in laparotomy cases. Table 4 indicates that the rates of physicians' sentence for malpractice was significantly higher in laparoscopy cases, compared with laparotomy ones.

Table 5 compares the type of occurred malpractice based on laparoscopy and laparotomy surgical proce- dures. The relative frequency of malpractice cases such as delayed "diagnosis" and "technical bugs of devices used during surgery" was significantly higher in laparoscopic surgeries, compared with laparotomy. However, “technician's or nurse's error" was significantly higher in laparotomy surgeries than laparoscopic cases. There was no significant relationship between the two surgical methods based on the variables of "malpractice from the legal point of view".

\section{Discussion}

In the current study, about half of the complaints were attributed to uterine and ovarian surgeries; therefore, females' ratio was higher than males on complaints in terms of gender. The obtained results were similar to those of Khavaninzadeh and Gholipour on medical complaints related to laparoscopic surgeries in the Medical Council of Tehran Province [12]. Approximately $67 \%$ of the complainants aged under 50 years; perhaps older patients were less interested to go to court. 
Table 2. The distribution of absolute and relative frequency of medical complaints in terms of the complication and failure

\begin{tabular}{|c|c|c|c|}
\hline \multirow{2}{*}{ Variable } & \multirow{2}{*}{ Classification } & \multicolumn{2}{|c|}{ No.(\%) } \\
\hline & & Yes & No \\
\hline \multirow{7}{*}{ Complicatio } & Infection & $(25.2) 93$ & $(74.8) 276$ \\
\hline & Bleeding & $(3.8) 14$ & $(96.2) 355$ \\
\hline & Rupture and damage to surrounding organs & $(34.7) 128$ & $(65.3) 241$ \\
\hline & & & \\
\hline & Death & $(6.8) 25$ & $(93.2) 344$ \\
\hline & Amputation or loss of the organ & $(30.4) 112$ & $(69.6) 257$ \\
\hline & Need repeat surgery & $(43.6) 161$ & $(56.4) 208$ \\
\hline \multirow{5}{*}{ Type of failur } & Surgeon's technical error during surgery & $(21.4) 79$ & $(78.6) 290$ \\
\hline & Delayed diagnosis & $(23) 85$ & (77)284 \\
\hline & & & \\
\hline & Technical bugs of used devices during surgery & $(2.2) 8$ & $(97.8) 361$ \\
\hline & Technician's or nurse's error & $(8.4) 31$ & $(91.6) 338$ \\
\hline \multirow{4}{*}{ Legal nature of } & Negligence & $(18.7) 69$ & $(81.3) 300$ \\
\hline & The lack of skills & $(10.6) 39$ & $(89.4) 330$ \\
\hline & The lack of compliance with government legislation & $(5.7) 21$ & $(94.3) 348$ \\
\hline & Recklessness & (29)107 & $(71) 262$ \\
\hline
\end{tabular}

Table 3. The comparison of postoperative complications in medical complaints related to laparoscopic and laparotomy surgeries

\begin{tabular}{|c|c|c|c|c|}
\hline \multirow{2}{*}{ Postoperative Complications } & \multirow{2}{*}{ Classification } & \multicolumn{2}{|c|}{ Type of Surgical Procedure No. (\%) } & \multirow{2}{*}{$\mathbf{P}$} \\
\hline & & Laparoscopy & Laparotomy & \\
\hline \multirow{3}{*}{ Infection } & Yes & $50(33.6)$ & $37(17.6)$ & \multirow{3}{*}{0.001} \\
\hline & & & & \\
\hline & No & $99(66.4)$ & $173(82.4)$ & \\
\hline \multirow{3}{*}{ Bleeding } & Yes & $8(5.4)$ & $6(2.9)$ & \multirow{3}{*}{0.22} \\
\hline & & & & \\
\hline & No & 141(94.6) & 204(97.1) & \\
\hline \multirow{2}{*}{$\begin{array}{c}\text { Damage or rupture to surrounding } \\
\text { visceral tissue }\end{array}$} & Yes & $66(44.3)$ & $58(27.6)$ & \multirow{2}{*}{0.001} \\
\hline & No & $83(55.7)$ & $152(72.4)$ & \\
\hline \multirow{3}{*}{ Death } & Yes & $49(32.9)$ & $57(27.1)$ & \multirow{3}{*}{0.24} \\
\hline & & & & \\
\hline & No & $100(67.1)$ & $153(72.9)$ & \\
\hline \multirow{3}{*}{ Need for repeat surgery } & & $85(57)$ & $72(34.3)$ & \multirow{3}{*}{$<0.001$} \\
\hline & & & & \\
\hline & & $64(43)$ & $138(65.7)$ & \\
\hline
\end{tabular}


Table 4. The distribution of absolute and relative frequencies of the final votes of the Commission based on the type of surgery

\begin{tabular}{ccccc}
\hline \multirow{2}{*}{ Type of Surgery } & \multirow{2}{*}{ Amount } & \multicolumn{2}{c}{ The Final Vote of the Commission } & \multirow{2}{*}{ P } \\
\cline { 3 - 4 } & & Sentenced & Acquitted & \\
\cline { 3 - 5 } Laparoscopy & No. (\%) & $94(63.1)$ & $55(36.9)$ & 0.002 \\
Laparotomy & & $98(46.7)$ & $112(53.3)$ & \\
\hline
\end{tabular}

Table 5. The comparative study of malpractice types based on the two methods of laparoscopic and laparotomy surgeries

\begin{tabular}{|c|c|c|c|c|}
\hline \multirow{2}{*}{ Type of Malpractice } & \multirow{2}{*}{ Classification } & \multicolumn{2}{|c|}{ Type of Surgical Procedure No. (\%) } & \multirow{2}{*}{$\mathbf{P}$} \\
\hline & & Laparoscopy & Laparotomy & \\
\hline \multirow{2}{*}{$\begin{array}{c}\text { Surgeon's technical error during } \\
\text { surgery }\end{array}$} & Yes & $38(25.5)$ & 40(19) & \multirow{2}{*}{0.14} \\
\hline & No & $111(74.5)$ & $170(81)$ & \\
\hline \multirow[b]{2}{*}{ Delayed diagnosis } & Yes & $52(34.9)$ & $30(14.3)$ & \multirow[b]{2}{*}{$<0.001$} \\
\hline & No & $97(65.1)$ & 180(85.7) & \\
\hline \multirow{2}{*}{$\begin{array}{l}\text { Technical bugs of used devices during } \\
\text { surgery }\end{array}$} & Yes & $7(4.7)$ & $1(0.5)$ & \multirow{2}{*}{0.01} \\
\hline & No & $142(95.3)$ & 209(99.5) & \\
\hline \multirow[b]{2}{*}{ Technician's or nurse' error } & Yes & $6(4)$ & 25(11.9) & \multirow[b]{2}{*}{0.009} \\
\hline & & & & \\
\hline
\end{tabular}

More than half of the explored complaints, consistent with the study by Khavaninzadeh et al. were against physicians practicing at private hospitals. Mitra Tadayon et al. investigated the associated factors of medical malpractice among obstetrics and gynecologists. They concluded most of the complaints were made in state hospitals, which was inconsistent with our results [1]. The reason for more complaints against physicians practicing at private hospitals in the current study can be that the patients in such hospitals endure high costs, compared with those. Therefore, they expect to receive better and high-quality healthcare services with fewer medical errors [12].

The final vote of the commission and the type of malpractice, as well as the complications of occurred infection or damage or rupture to adjacent visceral organs after laparoscopic surgery, were significantly higher than those of laparotomy procedures. In addition, due to such complications, the need to repeat surgery was also significantly higher in laparoscopy procedures. This suggest- ed that despite extensive advancements in technology and surgical services, complaints against physicians had an increasing trend [1]. In total, $30 \%$ of complaints were due to patients' death, similar to the results of Naderi et al. that found death as the cause of complaint in $49 \%$ of the cases [3]. The reason for the high death rate in the current study as well as other studies, to some extent, depends on the existence of a center for filing complaints.

\section{Conclusion}

Physicians' knowledge about legal medical issues and building intimate and trustful relationship with patients along with the provision of desirable healthcare services as well as compliance with standards and instructions of the Ministry of Health and other administrative and legal systems can be effective in reducing medical errors and filing complaints. 


\section{Ethical Considerations}

\section{Compliance with ethical guidelines}

All information was confidential, and relatives of the patient signed informed consent form.

\section{Funding}

This research did not receive any specific grant from funding agencies in the public, commercial, or not-forprofit sectors.

\section{Authors' contributions}

All authors contributed in designing, running, and writing all parts of the research.

\section{Conflict of interest}

The authors declared no conflict of interest.

\section{Acknowledgments}

The authors wish to thank the staff of the Legal Medicine Organization of Tehran Province for their cooperation with the project and providing the files.

\section{References}

[1] Kamiab F, Afshari P, Keikhahi B, Tadayon M, VahabiShekarloo T, Haghighizadeh MH. [A review of reasons of malpractice of obstetricians, gynecologists and midwives (Persian)]. Iranian Journal of Forensic Medicine. 2016; 22(3):165-71.

[2] Haghshenas M, Vahidshahi K, Amiri A, Rezaee M, Rahmani $\mathrm{N}$, Pourhossen M, et al. [Study the frequency of malpractice lawsuits referred to forensic medicine department and medical council, Sari, 2006-2011 (Persian)]. Journal of Mazandaran University of Medical Sciences. 2012; 21(86):253-60.

[3] Nadri S, Sheikhazadi A, Anbari K, Mikaeili R. [The evaluation of the causes of complaint to Khorramabad Medical Council Organization from 2006 to 2011 (Persian)]. Yafte. 2013; 15(1):25-31.

[4] Sadr SS, Ghadyani MH, Bagher Zadeh AA. [Assessment of records of complaints from medical malpractice in the field of orthopedic, in the coroner's Office of Forensic Medicine, province of Tehran, during 1988 to 2003 (Persian)]. Iranian Journal of Forensic Medicine. 2007; 13(2):78-86.

[5] Barzgar Bafrouee A, Zarenezhad M, Gholamzadeh S, Hosseini SMV, Gholi A, Gharedaghi J, et al. [Evaluation of orthopedic specialists' malpractice complaints referred to Legal Medicine Organization from 2008 to 2010 (Persian)]. Iranian Journal of Forensic Medicine. 2016; 22(1):55-66.
[6] Adibzadeh A, Ghadi Pasha M, Pour Amiri A, Nakhaei N, Samadi Rad B, Bastani M. [A study on medical malpractices ending to death and disability referred to Kerman Medical council's medical malpractices commission (Persian)]. Iranian Journal of Medical Law. 2012; 6(20):141-54.

[7] Azimi K, Poorbakhtiar M, Taghizadeh Z, Soltani K, Ghadipasha M, Daneshparvar H. [A Survey on various types of medical malpractice in relation with pregnancy and delivery, referred to relevant commissions of the Iranian Legal Medicine Organization (Persian)]. Iranian Journal of Forensic Medicine. 2017; 23(2):132-41.

[8] Daneshparvar H, Mahdavi A. [Investigation complaints from neurosurgeons referred to the office of the Forensic Medicine Committees of Tehran (Persian)]. Iranian Journal of Forensic Medicine. 2017; 23(3):215-24. [DOI:10.30699/epub. sjfm.23.3.215]

[9] Aghakhani N, Cheraghi R, Zarei A, Alinejad V, Nazimi N, Rahbar N, et al. [Study of causes of health providers' malpractices in records referred to Forensic Medicine Organization in Urmia, during 2009-2013 (Persian)]. Iranian Journal of Medical Law. 2017; 11(42):83-100.

[10] World Health Organization. 10 facts on patient safety. Geneva: World Health Organization; 2010.

[11] Sandberg EM, Bordewijk EM, Klemann D, Driessen SRC, Twijnstra ARH, Jansen FW. Medical malpractice claims in laparoscopic gynecologic surgery: A Dutch overview of 20 years. Surgical Endoscopy. 2017; 31(12):5418-26. [DOI:10.1007/ s00464-017-5624-8] [PMID] [PMCID]

[12] Khavanin-zadeh M, Gholipour F. Complaints related to laparoscopic surgery: A Survey of the files registered at Tehran Legal Medicine Center. International Journal of Hospital Research. 2013; 2(4):215-8. 
This Page Intentionally Left Blank 